\title{
Ore grade estimation using the imperialist competitive algorithm (ICA)
}

\author{
Reza Shamsi ${ }^{1} \cdot$ Hesam Dehghani ${ }^{2}$ (D) $\cdot$ Mohammad Jalali $^{3} \cdot$ Behshad Jodeiri Shokri $^{4}$ (D)
}

Received: 4 March 2021 / Accepted: 1 July 2021 / Published online: 16 July 2021

(C) Saudi Society for Geosciences 2021

\begin{abstract}
In this paper, a hybrid inverse distance weighted (IDW) and the imperialist competitive algorithm (ICA) was proposed for grade estimations in mining projects. Indeed, the coefficients of the IDW equation, power, and the influence distance were modified by applying the ICA algorithm. For this, an example was solved by using IDW, the ordinary kriging, and IDW-ICA. After successfully validating the IDW-ICA, the iron grades were estimated in the Baba Ali iron mine, the most prominent iron mine in the west of Iran. For this, after gathering data from thirty-two boreholes, the grade estimations were conducted using IDW, kriging, and IDW-ICA. Some statistical parameters, including the mean absolute percentage error (MAPE), root-mean-squared error (RMSE), and correlation coefficient, were used to compare the results. The higher value of the $R^{2}, 94.41 \%$, the lowest values of MAPE, 17.4\%, and RMSE, 4.19, of the proposed algorithm, revealed that the IDW-ICA could be applied as a new-fangled method for grade estimations in the mining projects.
\end{abstract}

Keywords Ore grade estimation · Imperialist competitive algorithm · Ordinary Kriging $\cdot$ Inverse distance weighted

\section{Introduction}

Ore grade estimation is one of the most critical stages of ore reserve evaluation and plays a vital role in mining operations. In many cases, faults, dikes, fractures, and complex structures

Responsible Editor: Murat Karakus

Hesam Dehghani

dehghani@ hut.ac.ir

Reza Shamsi

reza.shamsi@stu.hut.ac.ir

Mohammad Jalali

m.jalali@aut.ac.ir

Behshad Jodeiri Shokri

b.jodeiri@hut.ac.ir

1 Department of Mining Engineering, Hamedan University of Technology (HUT), Hamedan, Iran

2 Department of Mining Engineering, Hamedan University of Technology (HUT), Hamedan, Iran

3 Department of Mining and Metallurgical Engineering, Amirkabir University of Technology, Tehran, Iran

4 Department of Mining Engineering, Hamedan University of Technology (HUT), Hamedan, Iran make it particularly problematic to model the orebody. It is worth noting that geosciences' modeling is among the most complicated and difficult branches of mathematical geosciences' modeling due to heterogeneity of the earth structure and unique factors contributing to such these models. Different stages of a mining project, including the feasibility study, design, and planning, depend on the grade evaluation. Accordingly, one must obtain a reliable estimate of the ore grade to produce a realistic orebody reserve estimation. Generally, geostatistical methods represent the most common tools for predicting the grade variations and estimating the reserve of orebodies. Moreover, there are many pitfalls of using methods such as uncertainty of the assumptions made to determine the variogram parameters, time-intensiveness, and inability to provide accurate estimations if the regional variable spatial structure is inadequate. These disadvantages caused a great motivation for researchers toward using artificial intelligence-based (AI-based) estimators for grade evaluation instead of traditional geostatistical methods in recent years. For instance, Denby and Schofield (1995) applied the genetic algorithm (GA) to incorporate the grade variability into the planning process. In 2003, Ataei and Osanloo adopted the so-called golden-section search in optimizing the cutoff grade (Ataei and Osanloo 2003). Samanta et al. (2004) used multilayer neural networks (NNs) for modeling the grade 
across a gold orebody. Their study set the learning parameters through a trial-and-error procedure and proved the superiority of the built model over the geostatistical methods. Chatterjee et al. (2006) used a three-layer artificial neural network (ANN) to optimize grade evaluation in a limestone mine. The results revealed that the ANN method had higher efficiency compared to the geostatistical methods. In another research, Chatterjee et al. (2008) applied a genetic-neural hybrid algorithm for estimating the content of limestone in a limestone mine. The results highlighted the ability of the proposed algorithm to estimate the uncertainties. Tahmasebi and Hezarkhani (2010a) utilized an adaptive neuro-fuzzy inference system (ANFIS) to evaluate copper grade in Sarcheshmeh Copper Mine in southern Iran. Also, the obtained results were compared with other methods such as ANN and kriging. They found that the ANFIS had a better performance than the other methods in evaluating the grade. In another research in (2010b), Tahmasebi and Hezarkhani compared the performance of different learning algorithms on $\mathrm{NN}$ for iron ore grade estimation. Based on their results, it was found that the GA-based NN provides the best performance as a learning algorithm in their case. Their results showed that the GA-based NN could improve the network performance, lowering the mean squares error (MSE) while increasing the $R^{2}$ value. Li et al. (2013) used particle swarm optimization (PSO) to study copper grade on a hypothetical orebody. Soleimani and Jodeiri Shokri (2015) applied a combination of seismic and geostatistical methods to remove some ambiguities in heterogeneous oil reservoirs in the southwest of Iran. In another research, Soleimani and Jodeiri Shokri (2016) presented a mathematical-geological genetic model that was an advanced exploratory tool for better-evaluating chromite pods in the Sabzevar ophiolite complex in northeast of Iran. Gilani and Sattarvand (2016) evaluated the effect of grade uncertainties on the production planning for open-pit mines using the ant colony algorithm (OCA). Mohammadi et al. (2017) applied the imperialist competitive algorithm (ICA) to check for the influence of ore grade uncertainties on determining the cutoff grade. Jafrasteh et al. (2018) used the ANN, random forest algorithm (RFA), and gaussian processes to evaluate the copper grade. The results presented that the mentioned AI techniques could have better estimations than the traditional geostatistical methods. Mohammadi et al. (2018) utilized k-means and principal component analysis (PCA) methods to evaluate gold grade in the Khooni district in central Iran. They estimated the gold grade with a high correlation coefficient (91\%). Zerzour et al. (2020) used the geostatistical interpolation to evaluate the iron ore mixtures in Wenza open cast mine, northeast Algeria. They applied semi-variograms and kriging techniques to interpolate the needed values for mineral resource estimation. Afeni et al. (2021) investigated the reserve estimation methods such as triangular block and geostatistical. Then, they used the mentioned methods to estimate the Oyo-Iwa limestone deposit located in Nigeria. They concluded that the geostatistical method is more suitable, reliable, and preferable for grade estimation since it involves spatial modeling and cross-validated interpolation.

As found from the literature review, it seems that the AIs led to better results than conventional geostatistical methods. As a result, considering the importance of the uncertainty associated with the ore reserve estimation and its significant contribution to economic efficiency, a hybrid algorithm called IDW-ICA was proposed for the grade evaluation of the Baba-Ali Iron orebody in western Iran. For this purpose, the coefficients of the IDW equation, power, and the influence distance were modified by using the ICA.

\section{Materials and methods}

There are many methods for estimating a deposit reserve, which can be generally classified under two categories: geostatistical and classical methods. The classical methods employ classic statistics for grade evaluation. In contrast, the estimation in the geostatistical methods is based on the spatial structure of the medium. Indeed, geostatistical evaluation is a process where the value of a quantity at an unknown point can be estimated based on the value of the same quantity at known points. In general, geostatistics is a branch of statistics focusing on spatial or spatiotemporal datasets. It has initially been applied for predicting probability distributions of ore grades for mining operations.

\section{Inverse-distance weighted method}

As a conventional method for grade evaluation, the inverse distance weighted (IDW) method sets the contributions of surrounding grades into the grade of the central block dependent on the inverse of their distances to the central block. The closer blocks are likely to exhibit closer grades to that of the central block than the farther blocks. In order to place more emphasis on this inverse dependency, one may increase the weight in Eq. (1), which is done by changing the value of the power $n$ (Bartier and Keller 1996).

$g=\frac{\sum \frac{g_{i}}{d_{i}^{n}}}{\sum \frac{1}{d_{i}^{n}}}$

where

$g_{i}$ is the known grade of the ore;

$d_{i}$ is the influence distance from the known grade to the estimation point. 


\section{Kriging method}

The kriging is an estimation method that works based on a "weighted moving average" logic. It has been referred to as "the best unbiased linear estimation technique". Among other techniques, the kriging provides the error associated with each estimation to calculate the confidence interval for each estimation provided by the kriging. Some of the most important distinctions of the kriging compared to other estimation methods are as follows:

- In kriging, estimation at an unknown point is fully controlled by the spatial structure of the domain, while similar methods most frequently consider only one geometrical factor (e.g., distance) to calculate the weights so that the result exhibits no sensitivity to spatial variations of the orebody.

- As the spatial structure becomes weak (increased nugget effect), the role of sample position fades. Accordingly, under the complete nugget effect, all samples are weighted identically.

- With increasing the radius of influence, the weight of known samples at far distances to the considered block, i.e., unknown point, increases. In the meantime, assuming zero nugget effect and a radius of influence equal to the side of the block, the central block will yet bear higher importance, which is translated to higher values of weight.

- Although the inverse-distance weighted method performs as strongly as the kriging under continuity condition $\left(C_{0}=0\right)$, the presence of discontinuity (reflected as increased nugget effect) lowers the accuracy of the inverse-distance weighted method compared to the kriging.

The kriging calculations can be simply explored by referring to a handful of geostatistical textbooks, where the solution and determination of the estimated grades are well discussed. Given that such equations and associated challenges are beyond the scope of the present article, we herein ignore them and instead only refer to the main features of this method:

- The weights are determined in such a way not only to keep the solution unbiased but also to minimize the variance.

- The level of error associated with each estimation is also provided.

- In the estimation at an actual sampled point, the estimated value must be equal to the measured value, making a variance of zero at such a point.

- The kriging error is a function of the variogram properties (spatial structure), the geometry of the estimated blocks, and the block used to obtain the estimations rather than the actual data values.
- Kriging results are additive, meaning that kriging in some small blocks can be added up to obtain estimations over a larger block composed of all the small blocks. The blocks were graded using the kriging based on the parameters of the obtained variogram and the kriging.

\section{Imperialist competitive algorithm (ICA)}

Searching for an appropriate solution is a challenging inevitable task to address in many engineering problems yet. Accordingly, many search algorithms have been proposed for finding a solution for such problems. Evolutionary algorithms are a significant class of search algorithms where the evolutionary rules of nature are utilized to find the optimal solution. Some of the most applicable evolutionary algorithms in geosciences are the GA, ACO, ICA, bat algorithm (BA), and biogeography-based optimization (BBO). Human social behaviors have been used in the ICA. In 2007, this algorithm was introduced by Atashpaz-Gargari and Lucas. ICA is a robust optimization algorithm where socio-politic phenomena are mathematically modeled (Atashpaz-Gargari and Lucas 2007; Biabangard-Oskouyi et al. 2009; Jodeiri Shokri et al. 2020). In the ICA, an initial population is generated by selecting several countries randomly at the first step. Subsequently, a cost function is established, and the entire pool of the countries is classified into imperialists and colonies. Indeed, the more powerful countries are classified as imperialists while the other countries are grouped as colonies. Once the imperialists are recognized, recognizing their powers, each of the other countries is captured by an imperialist. An imperialist and its captured colony(ies) are collectively referred to as an empire. Another approach to the assignment of the colonies to the imperialists is to do it depending on their normalized cost (Eq. (2) (Atashpaz-Gargari and Lucas 2007):

$C_{n}=\max _{i}\left\{c_{i}\right\}-c_{n}$

where

$c_{n} \quad$ is the cost of the $n^{\text {th }}$ imperialist;

$\max _{i}\left\{c_{i}\right\} \quad$ is the maximum cost among the imperialists;

$C_{n} \quad$ is the normalized cost on the $n^{\text {th }}$ imperialist.

The normalized relative power of each imperialist, which is, indeed, the ratio of the number of its colonies to the total number of colonies, can be determined through Eq. (3) (Atashpaz-Gargari and Lucas 2007).

$P_{n}=\left|\frac{C_{n}}{\sum_{i=1}^{N_{i n p}} C_{i}}\right|$

Moreover, the initial number of colonies of an empire is calculated by Eq. (4): 
Fig. 1 Different steps of the proposed algorithm

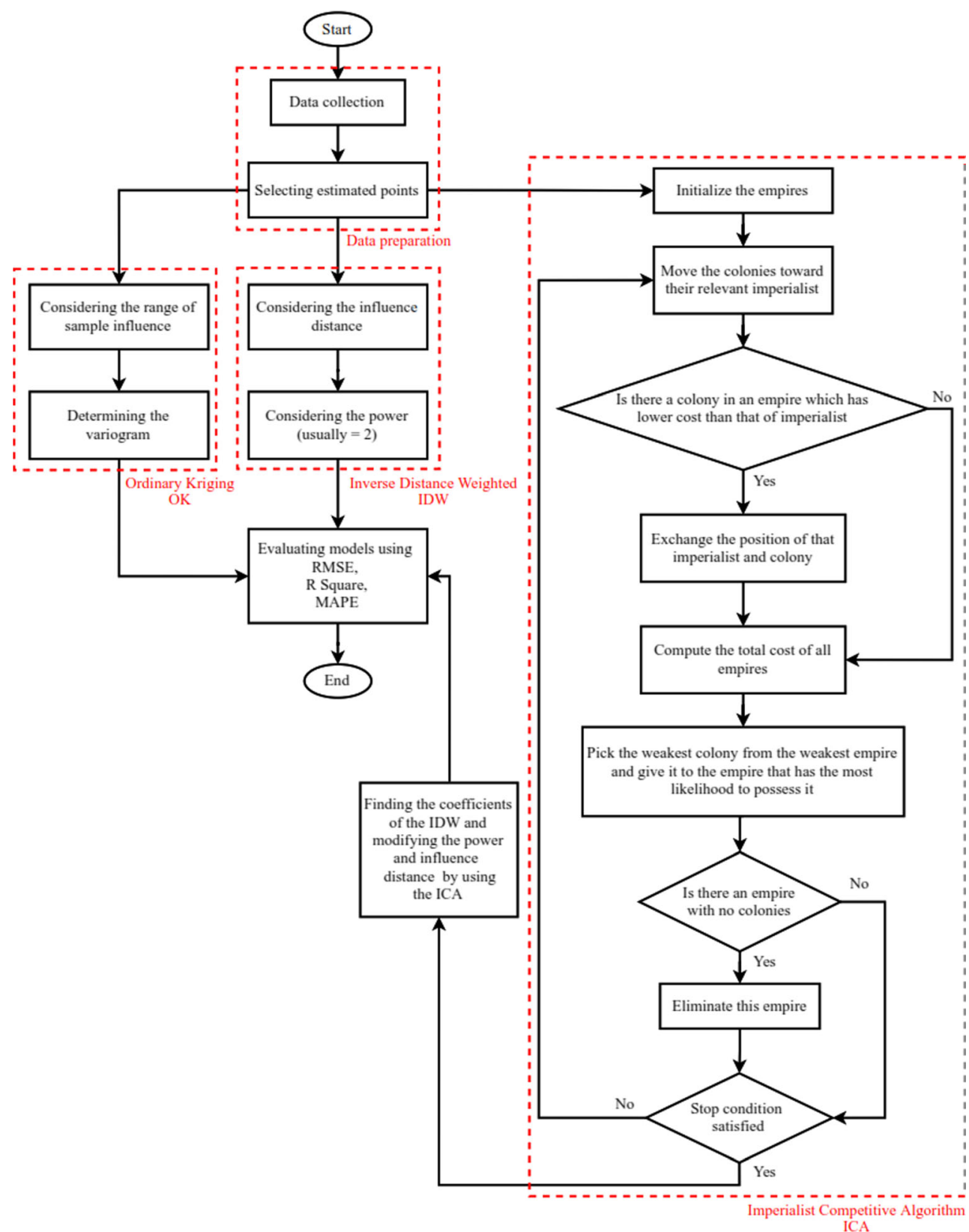

ICA
$N . C_{\cdot n}=\operatorname{round}\left\{P_{n} \cdot N_{c o l}\right\}$

where

$N_{c o l}$ : is the total number of colonies in the initial population of countries.

Considering the value of $N . C_{\cdot n}$ for each empire, some initial colonies are selected at random and captured by the $n$ th imperialist. Then, an attempt is made to move the imperialist as close to the respective colonies as possible to analyze their culture and social structure, followed by moving the colonies toward the respective imperialist (Atashpaz-Gargari and Lucas 2007). It is worth noting that there may be cases where a colony reaches a point in the cost function at which the associated cost is lower than that of the imperialist. In such cases, the imperialist and the colony are swapped. The algorithm proceeded with the imperialist at the new position from which it applies the assimilation policy to its colonies. In order to evaluate the cost function, total empire cost is calculated through Eq. (5) (Atashpaz-Gargari and Lucas 2007).

$$
\begin{aligned}
& \text { T.C. }{ }_{\cdot n}=\operatorname{Cost}_{\left(\text {imperialist }_{n}\right)+\xi} \\
& \times \text { mean }\left\{\text { Cost }\left(\text { colonies of empire }{ }_{n}\right)\right\}
\end{aligned}
$$

where

$\xi$ : is a constant value between 0 and 1 (close to 0 ). 
Table 1 Coordinates and ore grades of the bores shown in Fig. 1 (Hughes and Davey 1979)

\begin{tabular}{|c|c|c|c|c|c|c|c|}
\hline \multirow[t]{2}{*}{ Borehole } & \multicolumn{2}{|c|}{ Coordinates } & \multirow[t]{2}{*}{ Grade $(\mathrm{Cu} \%)$} & \multirow[t]{2}{*}{ Borehole } & \multicolumn{2}{|c|}{ Coordinates } & \multirow[t]{2}{*}{ Grade $(\mathrm{Cu} \%)$} \\
\hline & East & North & & & East & North & \\
\hline $\mathrm{C} 1$ & 1100 & 1200 & 0.719 & $\mathrm{C} 27$ & 900 & 1200 & 0.453 \\
\hline $\mathrm{C} 2$ & 1500 & 1200 & 0.893 & $\mathrm{C} 28$ & 600 & 700 & 0.409 \\
\hline $\mathrm{C} 3$ & 1100 & 800 & 0.638 & $\mathrm{C} 29$ & 1300 & 800 & 1.615 \\
\hline $\mathrm{C} 4$ & 1100 & 400 & 0.188 & $\mathrm{C} 30$ & 1700 & 800 & 0.465 \\
\hline $\mathrm{C} 5$ & 1500 & 400 & 0.395 & C31 & 1100 & 600 & 0.063 \\
\hline C6 & 1500 & 800 & 0.765 & $\mathrm{C} 32$ & 900 & 400 & 0.224 \\
\hline $\mathrm{C} 7$ & 500 & 900 & 0.644 & $\mathrm{C} 33$ & 1300 & 400 & 0.027 \\
\hline $\mathrm{C} 8$ & 900 & 1000 & 1.365 & $\mathrm{C} 34$ & 1100 & 200 & 0.225 \\
\hline C9 & 1300 & 1000 & 1.335 & $\mathrm{C} 35$ & 1300 & 1400 & 0.475 \\
\hline $\mathrm{C} 10$ & 1700 & 1000 & 0.072 & $\mathrm{C} 36$ & 700 & 1400 & 0.717 \\
\hline $\mathrm{C} 11$ & 500 & 1600 & 0.396 & $\mathrm{C} 37$ & 500 & 1400 & 0.320 \\
\hline $\mathrm{C} 12$ & 900 & 1600 & 0.377 & $\mathrm{C} 38$ & 300 & 1400 & 0.392 \\
\hline $\mathrm{C} 13$ & 1100 & 1600 & 0.427 & C39 & 400 & 700 & 0.476 \\
\hline $\mathrm{C} 14$ & 1500 & 1600 & 0.140 & $\mathrm{C} 40$ & 400 & 1050 & 0.102 \\
\hline C15 & 900 & 1400 & 0.806 & C41 & 700 & 1000 & 0.023 \\
\hline C16 & 1100 & 1400 & 0.889 & C42 & 1100 & 1000 & 0.915 \\
\hline C17 & 1300 & 1200 & 1.009 & $\mathrm{C} 43$ & 1500 & 1000 & 0.519 \\
\hline $\mathrm{C} 18$ & 1700 & 1200 & 0.089 & C44 & 1900 & 1000 & 0.040 \\
\hline C19 & 1900 & 1200 & 0.092 & $\mathrm{C} 45$ & 1900 & 800 & 0.034 \\
\hline C20 & 600 & 1900 & 0.175 & C46 & 900 & 800 & 0.258 \\
\hline $\mathrm{C} 21$ & 1100 & 1800 & 0.489 & C47 & 900 & 600 & 0.165 \\
\hline C22 & 800 & 1800 & 0.417 & C48 & 1300 & 600 & 0.406 \\
\hline $\mathrm{C} 23$ & 200 & 1600 & 0.215 & C49 & 1500 & 600 & 0.996 \\
\hline $\mathrm{C} 24$ & 700 & 1600 & 0.685 & $\mathrm{C} 50$ & 1700 & 600 & 0.012 \\
\hline $\mathrm{C} 25$ & 500 & 1200 & 0.230 & C51 & 500 & 500 & 0.228 \\
\hline C26 & 800 & 1200 & 0.833 & & & & \\
\hline
\end{tabular}

Fig. 2 Locations of the bores at the bench 5140 (Hughes and Davey 1979)

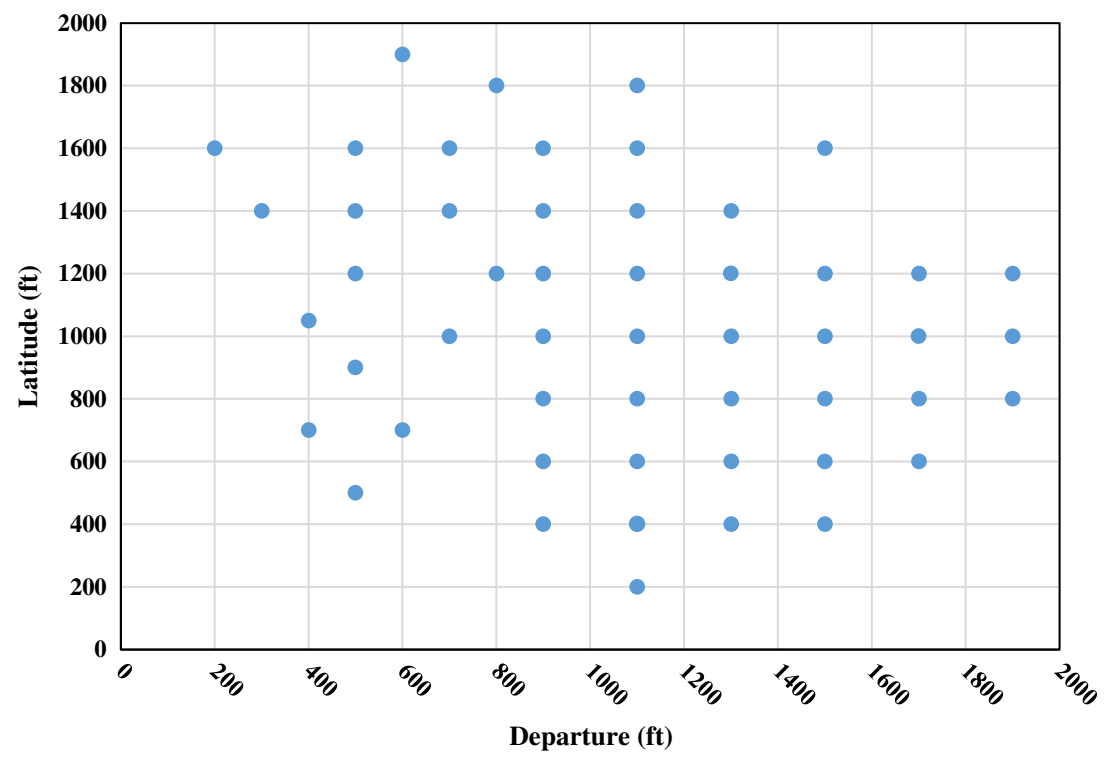


Fig. 3 Locations of estimation bores

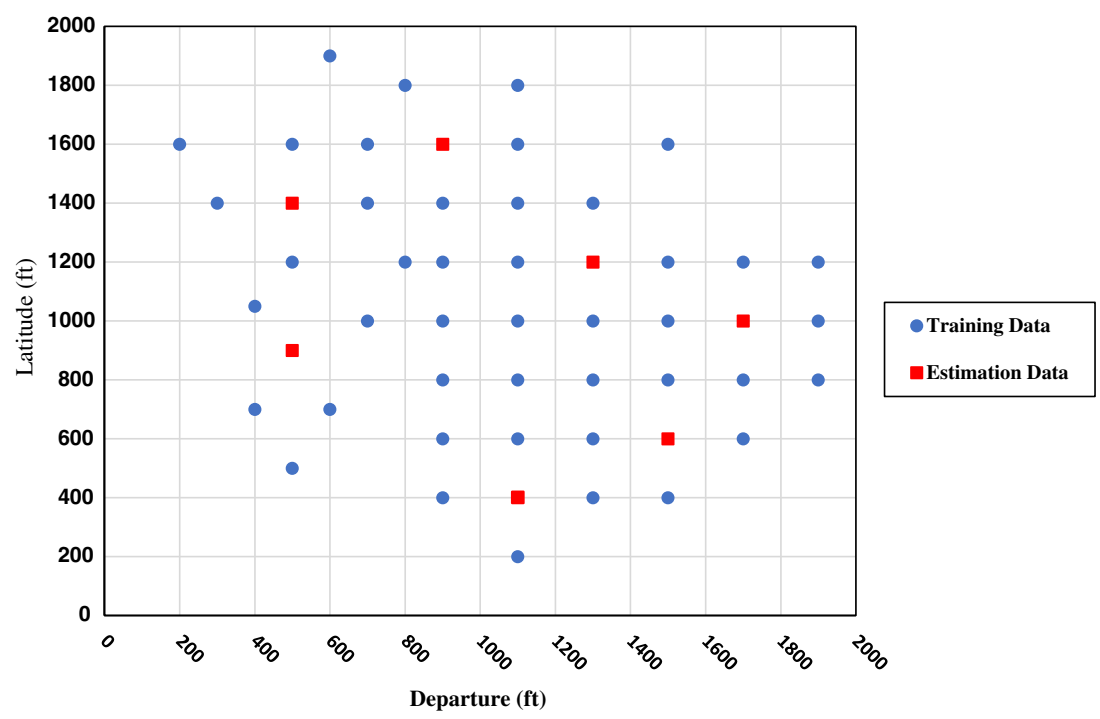

Once finished with calculating the cost of each empire, the colonies belonging to weaker empires are eliminated and captured by the more powerful empires.

The attraction or competition process is iterated among the imperialists. At each iteration, the least potent imperialist loses a colony. The separate colony from the weakest imperialist is the weakest among the colonies of that imperialist. Subsequently, all empires start a competition for capturing the colonies. The empire that lost all of its colonies was eliminated and captured by another imperialist to serve as a colony. This process is continued until the single most powerful imperialist is achieved (Atashpaz-Gargari and Lucas 2007). In order to have the algorithm stopped somewhere, some stopping criterion is considered. This may be achieving a particular number of iterations or processing time. Accordingly, the algorithm is terminated once either the stopping criterion is met or a single final imperialist is reached.

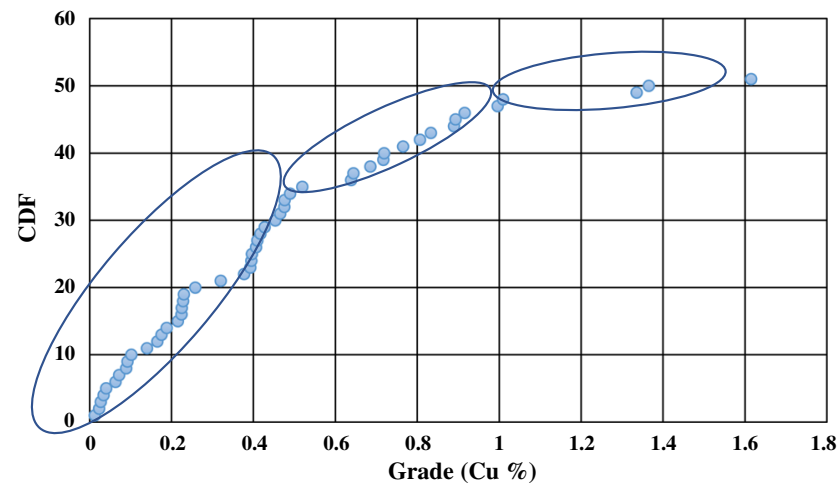

Fig. 4 Cumulative Distribution Function (CDF) of the database utilized for pattern recognition

\section{Proposed algorithm}

Regarding the mentioned problems and the importance of providing an appropriate and accurate estimation of ore grade for reserve design, the present paper attempts to present a hybrid IDW-ICA algorithm to attenuate the ore grade evaluation error. In order to demonstrate the performance of the hybrid algorithm, firstly, its different steps were applied on a hypothetical case, followed by using the algorithm to evaluate the ore grade in an actual mine. Different steps of the proposed algorithm are shown in Fig. 1.

Step 1: data gathering In this section, different steps of grade evaluation are described using the data presented by Hughes and Davey (1979). Locations of the bores are presented in Fig. 2 and Table 1.

Step 2: determining the evaluation points In order to investigate the performance of the proposed algorithm, seven boreholes, including $\mathrm{C} 4, \mathrm{C} 7, \mathrm{C} 10, \mathrm{C} 12, \mathrm{C} 17, \mathrm{C} 37$, and $\mathrm{C} 49$, were selected for copper grade evaluation. These seven boreholes were selected among all 51 boreholes in such a way to cover the entire model. Locations of the selected boreholes are marked with red squares in Fig. 3.

Step 3: running the model and grade evaluation In this step, the ore grade at the selected bores was evaluated using the two conventional ore evaluation techniques, the kriging and the IDW methods, and the ICA algorithm.

\section{Kriging}

The grade-count fractal method is a technique for population identification in geoscience data, which works based on the cumulative frequency of the data. The discontinuities seen on 
Fig. 5 Two perpendicular variograms prepared for determining the search ellipsoid
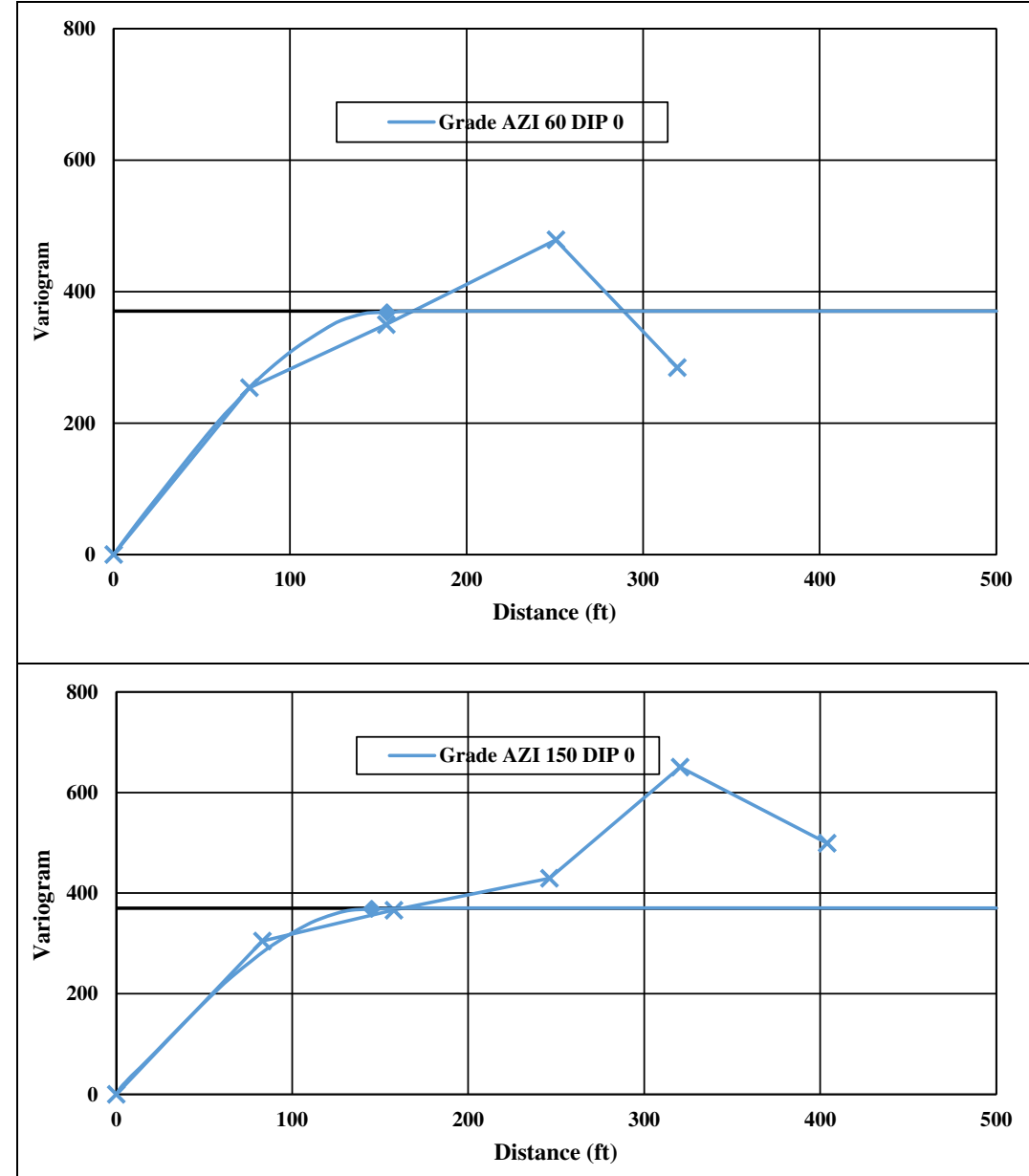

the respective histogram mark the changes in the populations (Fig. 4). As seen on this histogram, three distinct populations (i.e., dimensions) were identified on the data from the studied area. This classification was then used for scaling the original data and the estimation results.

Fig. 6 Anisotropic search ellipsoid

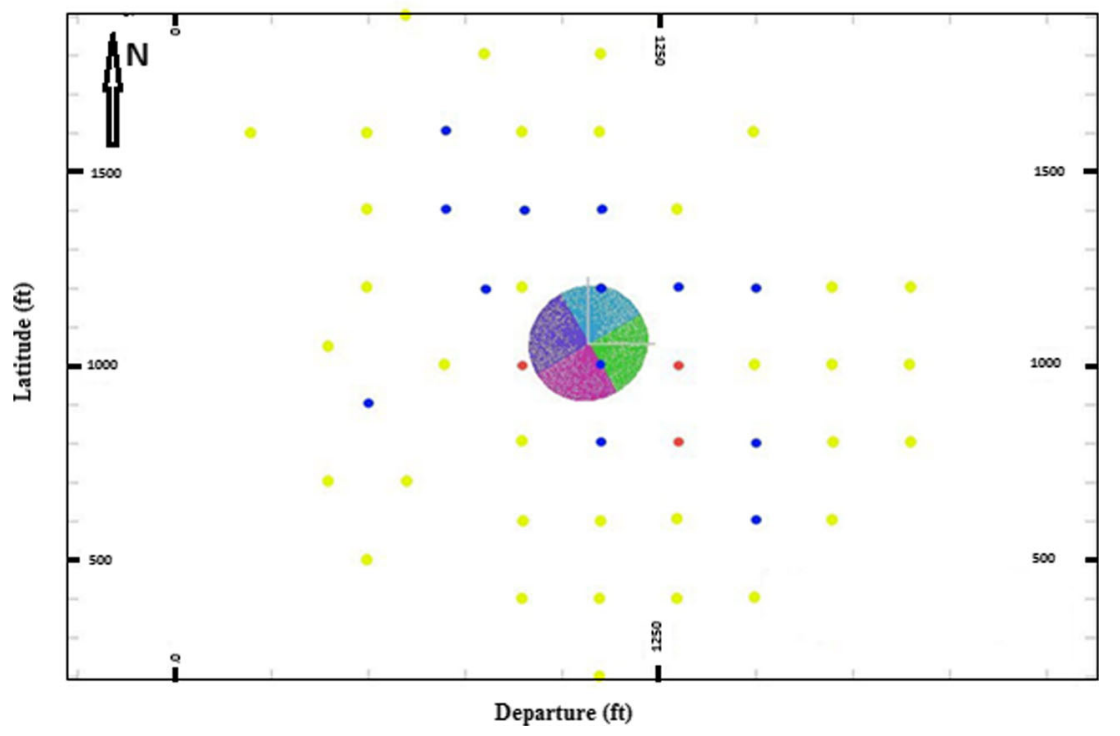


Table 2 Cross-validation statistics for grade estimation

\begin{tabular}{ll}
\hline Cross-validation statistics or grade & \\
\hline Number of estimated samples & 50 \\
Number of not estimated samples & 1 \\
Mean of actual values & 0.47404 \\
Mean of estimated values & 0.51214977 \\
Mean difference (act - est) & -0.03810977 \\
Mean difference (as \% of actual) & -8.039 \\
Mean absolute difference & 0.25186146 \\
The variance of actual values & 0.1387426 \\
The variance of estimated values & 0.0871345 \\
Correlation coefficient & 0.543 \\
Kriging variance & \\
Mean of estimated KV from the model & 370.310999 \\
Mean of squared differences & 0.10781973 \\
Ratio & 3434.538 \\
Regression equation & \\
Actual & $0.12281932+\underline{0.68577729} \times$ estimate \\
Standard error & 0.31267247 \\
\hline
\end{tabular}

the azimuth of the vector $h(\Phi)$, the respective tolerances, bandwidth, number of lags, and the lag spacing. This software could further be used to perform the kriging to obtain grade estimates and distribute the resultant estimation error.

Variogram is used to express the spatial relationship between the grade (or any other property) at different points across a region, making it an essential tool in geostatistical studies. The variogram is of particular interest for mining engineers, as it can be utilized to investigate essential properties of the orebody that affect its estimation. These include the mineralization continuity, radius of effect, and isotropic nature of the orebody. These properties can be studied by analyzing the similarities and dissimilarities of the grades at different points of the orebody at a predefined distance $h$ to one another. In general, in the framework of the inherent hypothesis, the variogram is a second-reorder momentum defined as follows:

$2 \gamma(h)=\operatorname{Var}[Z(x+h)-Z(x)]=E[Z(x+h)-Z(x)]^{2}$.

For a general case, it can be written as follows (Eq. (7)):

$2 \gamma(h)=\frac{1}{V} \oint_{V}[Z(x+h)-Z(x)]^{2} d x$

Table 3 Result of Jack-knife kriging (grade versus estimated grade)

\begin{tabular}{lll}
\hline NAME & Grade & GradeEST \\
\hline Minimum & 0.012 & 0.040 \\
Maximum & 1.615 & 1.312 \\
Mean & 0.474 & 0.512 \\
Correlation coefficient & 0.543 & \\
\hline
\end{tabular}

where

$\mathrm{V}$ : is the geometric field (e.g., the volume of the block to be estimated) of the point $x$. Generally, the symbol $*$ is used to indicate the estimated (calculated) values in geostatistics.

Therefore, the empirical variogram can be evaluated with Eq. (8):

$2 \gamma^{*}=\frac{1}{N(h)} \sum[Z(x+h)-Z(x)]^{2}$

where

$N(h)$ is the number of sample pairs used in the calculations for each lag, $h$. That is, the number of pairs is a function of $h$. Typically, the larger the value of $h$, the lower will be the number of pairs.

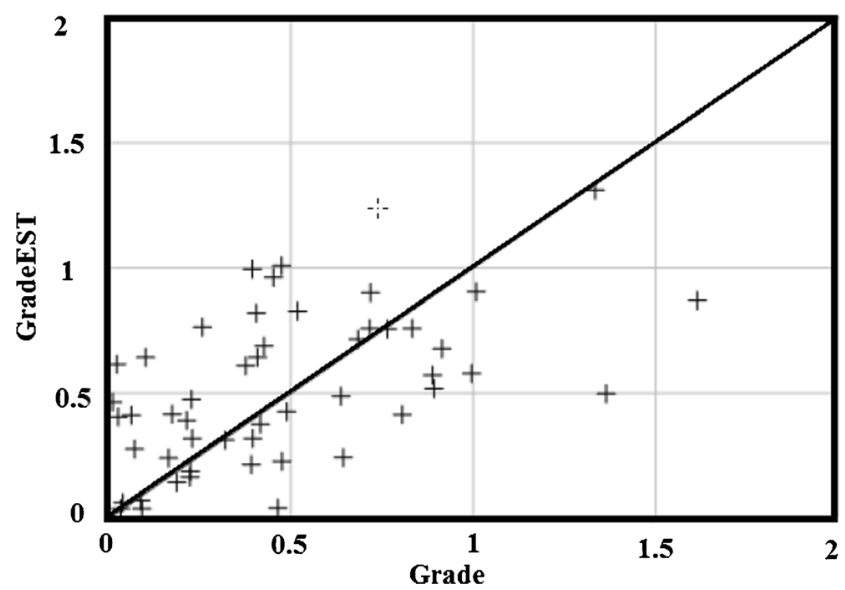

Fig. 7 Result of Jack-knife kriging (actual data versus estimated data) 
Fig. 8 Histogram of residual distribution of the Jack-knife kriging algorithm (the results almost show the estimator is unbiased)

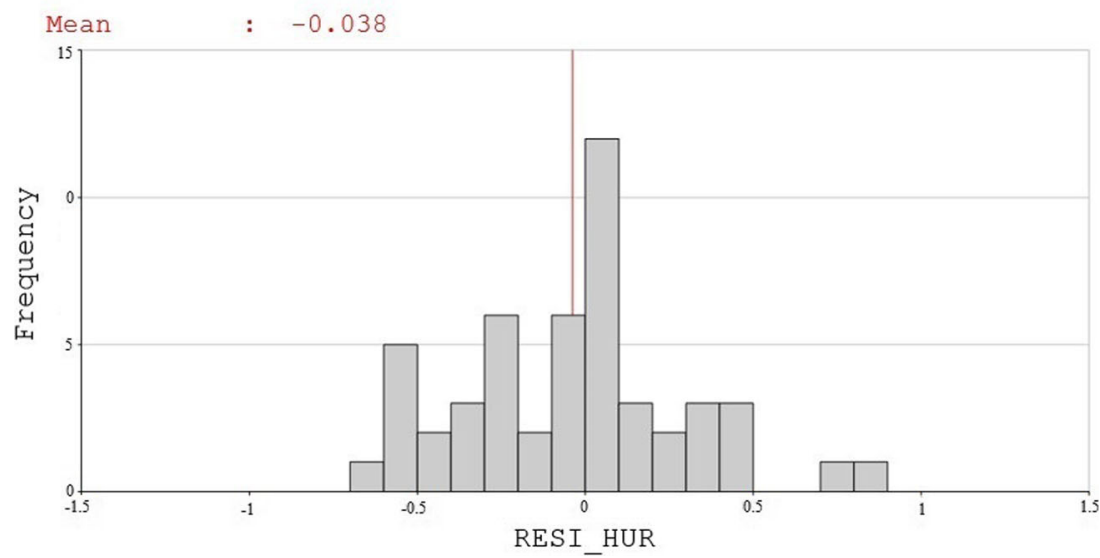

Once finished with the variography at different directions, two normal variograms were found and used to establish the searching ellipse (Fig. 5).

Figure 6 shows the searching ellipse, which is a basis of geostatistical estimations through kriging. The results of variography processing such as the anisotropy, axis rotation direction, anisotropy radius, the nugget and ceiling effects have been involved in this searching ellipse.

In the kriging estimations, the importance of this control is even doubled. It is due to the significant dependence of the accuracy of the results to the considered model. In addition, variogram modeling is a sensitive process. The exact shape of the variogram is not previously known at all. The model provides no more than an approximation of the actual variogram function. Validity control refers to the estimation at each of the sampled points across a region using the value at neighboring points (without considering the actual value at the considered point) using the kriging method. The estimated values are compared to the actual data to find whether the variogram model of the neighborhood search parameters considers the distance-deponent variations appropriately. Usually referred

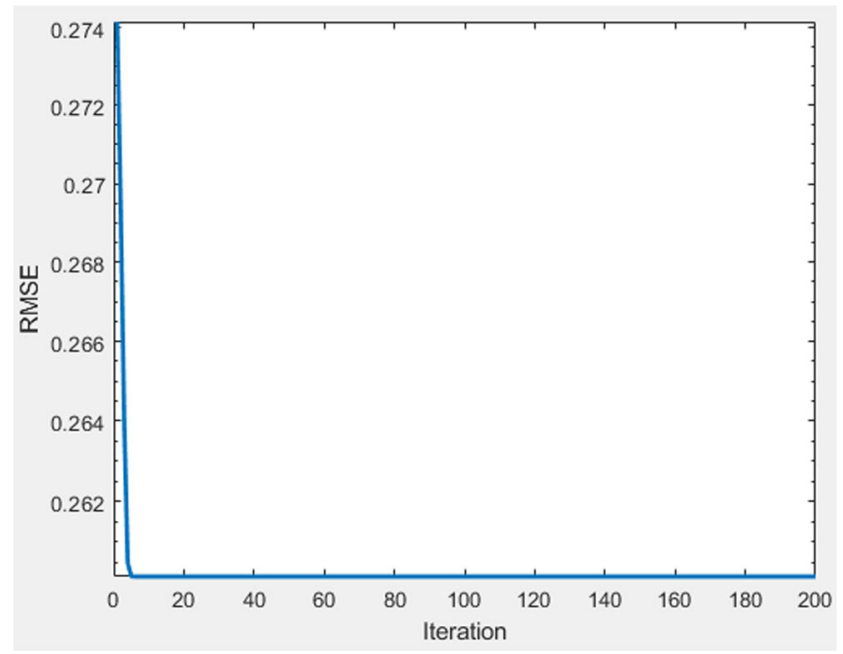

Fig. 9 A decreasing trend of RMSE during the course of performing the ICA to as the jackknife method, this kriging-based estimation method evaluates a particular property at an unknown point using the neighboring samples (Fig. 7). By using the jackknife method, the grade was estimated at the selected boreholes, with the results presented in Fig. 7 and Tables 2 and 3. The results revealed that the variogram parameters were $55 \%$ valid for block grade evaluation, a desirable level of validity. This justified the use of the variogram parameters for the grade evaluation of exploratory blocks.

Residuals analysis is used to investigate biases of the estimator in geostatistical modeling. Accordingly, an estimator can be recognized as unbiased if the histogram of the residuals (difference between actual data and estimated values) is distributed as a normal function around a mean value of zero with an adequately low standard deviation (Fig. 8).

\section{IDW method}

As mentioned, this method estimates the grade using two parameters: power and radius of influence. In the following example, the power and the radius of influence were 2 and 250 $\mathrm{ft}$, respectively (Eq. (9)).

$$
g=\frac{\sum \frac{g_{i}}{d_{i}^{2}}}{\sum \frac{1}{d_{i}^{2}}}
$$

\section{ICA}

In the ICA, to minimize the RMSE, Eq. (10) was taken as the objective function. The coding was performed in https:/www. mathworks.com/products/matlab/student.html.

$R M S E=\sqrt{\frac{1}{n} \sum_{i=1}^{n}\left(P_{i}-O_{i}\right)^{2}}$ 
Fig. 10 Distribution of the bores and the radius of influence of the validation bores

where

$n \quad$ is the number of data points;

$P_{i} \quad$ is the estimated result;

$O_{i}$ is the actual data.

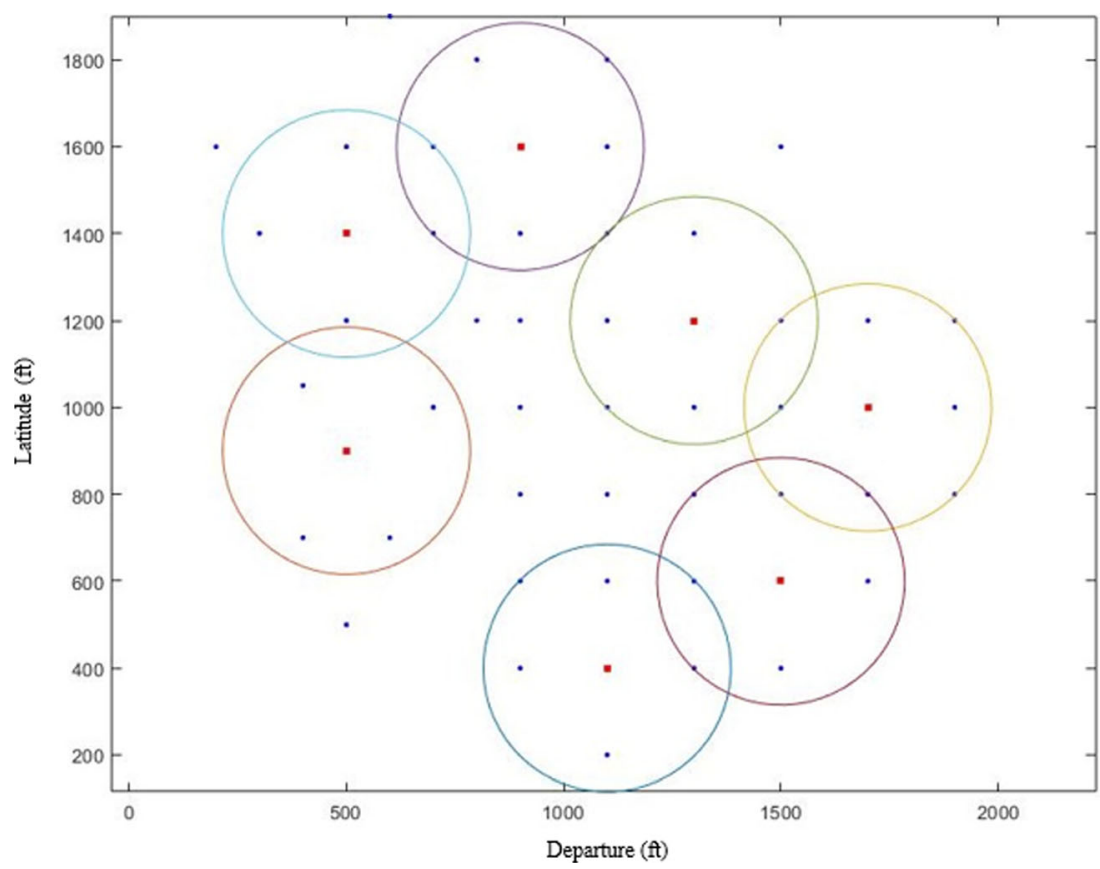

In this stage, fifty countries, ten imperialists, and 200 iterations were considered in the model built in this stage. The problem was solved by going through the following steps:

- Determining and finding the coefficients of IDW equation, power, and the influence distance by applying the ICA algorithm;
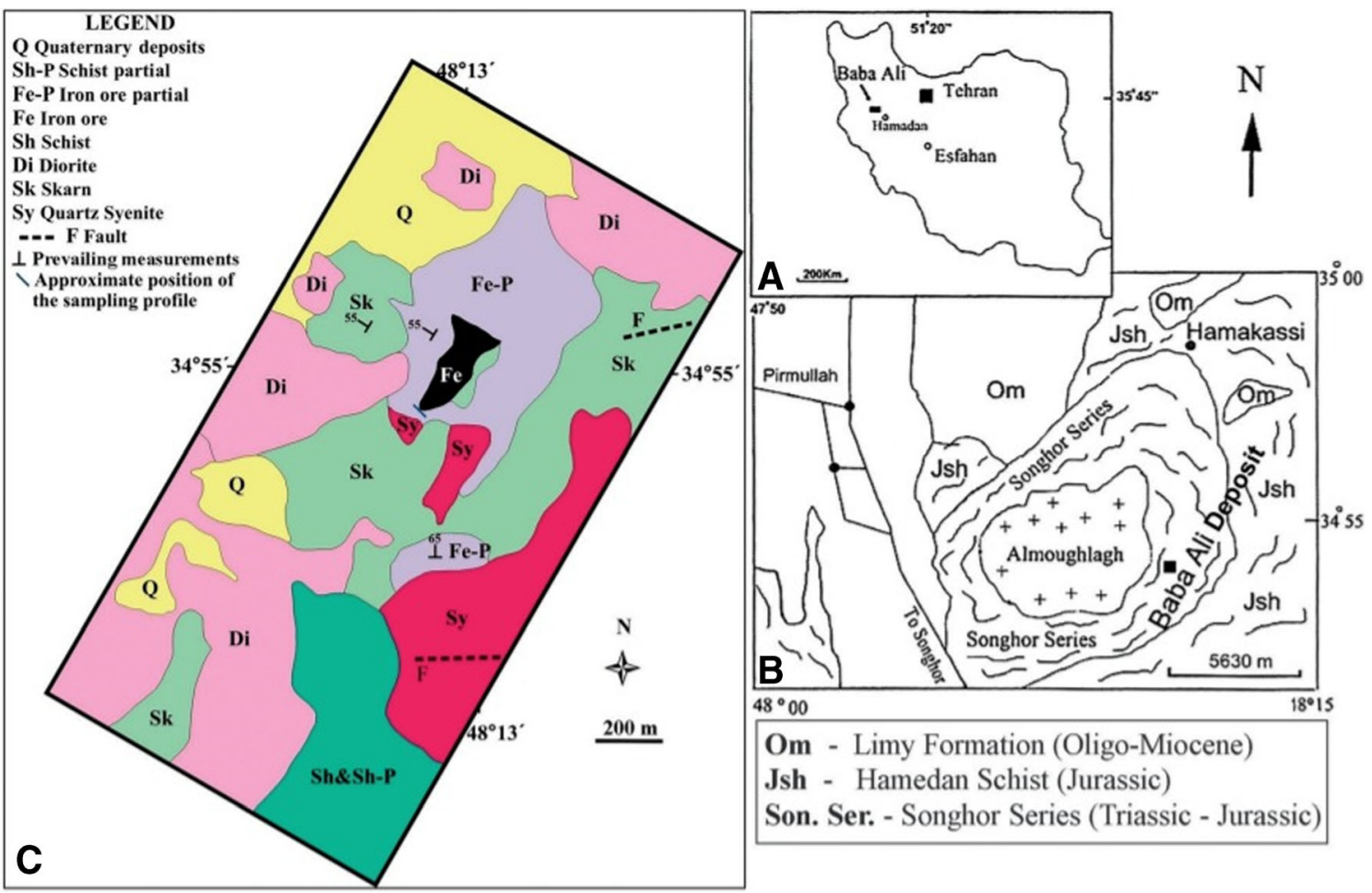

Fig. 11 (a) The location map of the Baba Ali iron mine; (b) geological map of the Baba Ali iron mine; (c) simplified geological map of the Baba Ali region (Zamanian and Radmard 2016) 
- Grade evaluation by suggesting the proposed algorithm, the IDW-ICA;

- Presenting the results.

The decreasing trend of RMSE during performing the ICA is shown in Fig. 9. The distribution of the boreholes, the power, and the influence distance of the estimated grade have been illustrated in Fig. 10.

After 200 iterations of the ICA in Matlab, the results showed that the most suitable influence distance and power were $281.85 \mathrm{ft}, 131.05$, respectively. Also, indeed, the most appropriate modified coefficients of the IDW equation have been suggested using ICA. As a result, the following IDW-ICA equation has been proposed for grade evaluation:

$g=\frac{\sum \frac{0.9319 \times g_{i}}{d_{i}^{131.0518}}}{\sum \frac{0.7469}{d_{i}^{131.0518}}}$

Step 4: Comparing the results In order to validate the proposed method, the estimation error was calculated using RMSE (Eq. (10), coefficient of determination (Eq. (12)), and mean absolute percentage error (MAPE) (Eq. (13)).

$$
\begin{gathered}
R^{2}=1-\frac{\sum_{i=1}^{n}\left(P_{i}-O_{i}\right)^{2}}{\sum_{i=1}^{n}\left(x_{i}-\bar{x}\right)^{2}} \\
M A P E=\frac{1}{n} \sum_{i=1}^{n} \frac{\left|P_{i}-O_{i}\right|}{P_{i}}
\end{gathered}
$$

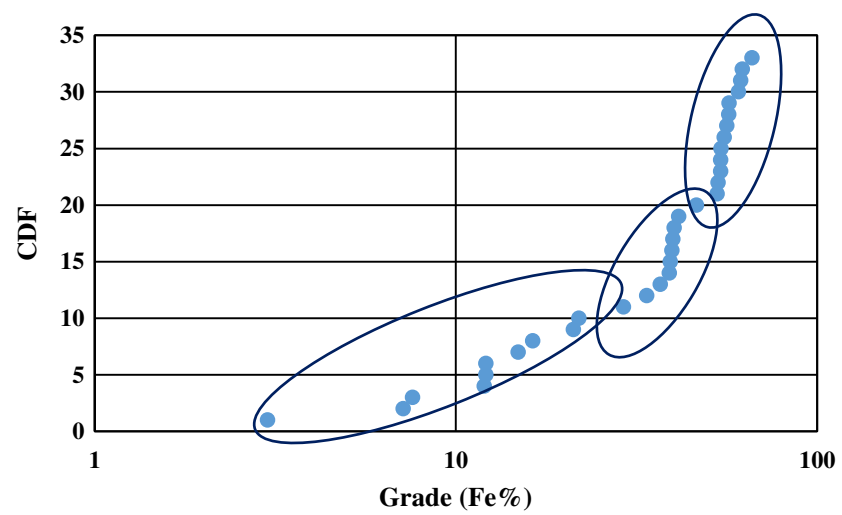

Fig. 13 Cumulative Distribution Function (CDF) of the database utilized for pattern recognition

where

$\bar{x}$ : is mean value of actual $x_{i}$ values.

The estimated grade using the IDW, the kriging, and the IDW-ICA have been presented in Table 2. The boreholes, including $\mathrm{C} 4, \mathrm{C} 7, \mathrm{C} 10, \mathrm{C} 12, \mathrm{C} 17, \mathrm{C} 37$, and $\mathrm{C} 24$, were chosen for analyzing the IDW, the kriging, and the ICA methods. According to Hughes and Davey (1979), in the IDW, the power was 2 while the efficient distance was $250 \mathrm{ft}$. Also, the Datamine studio software has been utilized for grade estimation by applying the kriging technique. Along with these two methods, the ICA algorithm for finding the best coefficients of the IDW equation. After running the ICA codes in the https://www.mathworks.com/products/matlab/student.html, the radius of influence distance and power were found 277 and 2 in the IDW equation, respectively. The real data refers to the actual copper grade in the boreholes. Some statistical parameters such as determination of coefficients ( $R$-squared),
Fig. 12 Coordinates of the bores along with section \#2390

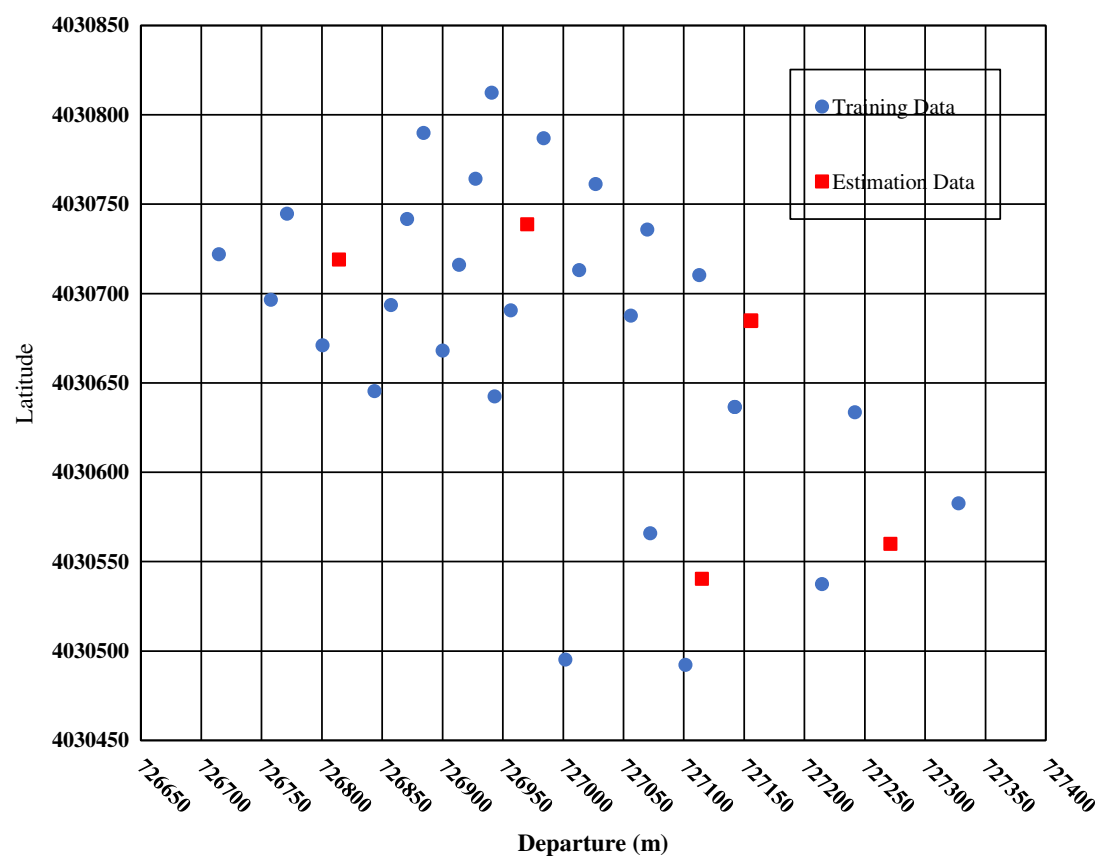


Fig. 14 Two perpendicular variograms ((a) azimuth $75^{\circ}$ and (b) azimuth $165^{\circ}$ ) prepared for determining the search ellipsoid

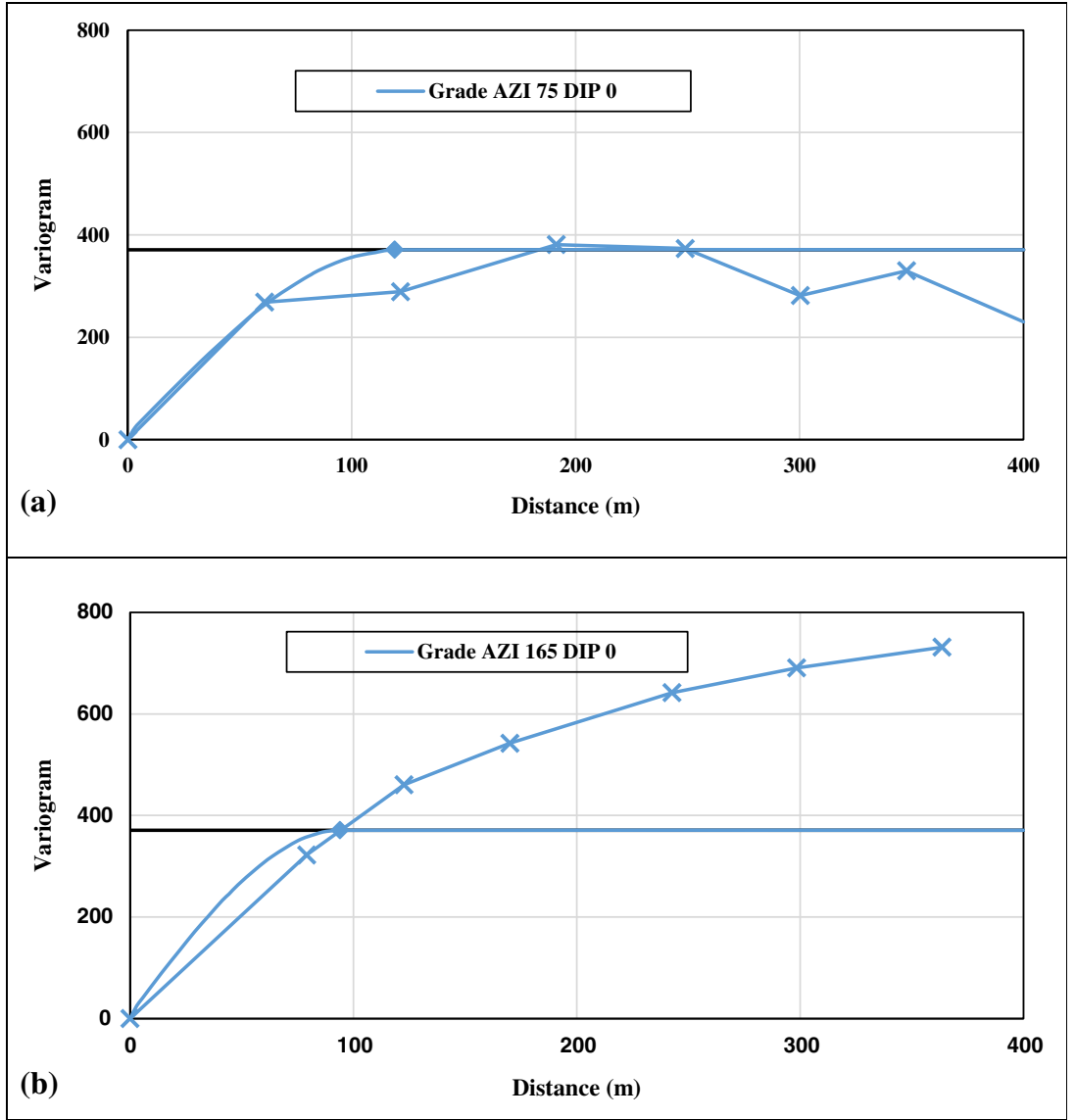

RMSE, and MAPE were considered for evaluating the performance of the methods. Indeed, it was an attempt to find out that if the IDW-ICA estimations were close to other convectional estimations methods such as the IDW and the kriging or not. As found from the table, the $R$-squared values in the
IDW, the kriging, and the IDW-ICA were 22.83, 48.02, and 44.34, respectively. Moreover, the RMSE values in the methods were $0.31,0.25$, and 0.26 . The results revealed that the proposed algorithm, IDW-ICA, had a better result than IDW. Moreover, it could estimate the grade close to the kriging technique.
Fig. 15 Anisotropic search ellipsoid

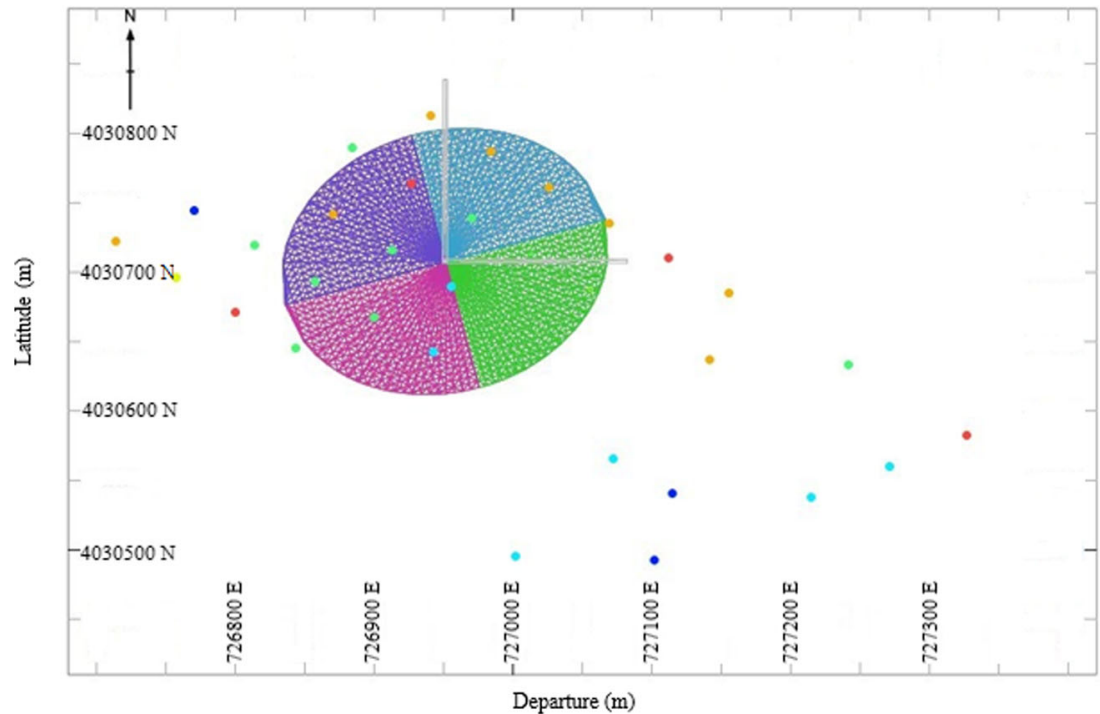


Table 4 The obtained results

\begin{tabular}{|c|c|c|c|c|}
\hline Parameter & Real grade of $\mathrm{Cu}$ & IDW & Kriging & $\begin{array}{l}\text { IDW- } \\
\text { ICA }\end{array}$ \\
\hline Borehole C4 & 0.188 & 0.1347 & 0.144 & 0.1681 \\
\hline Borehole C7 & 0.644 & 0.2346 & 0.2432 & 0.3776 \\
\hline Borehole C10 & 0.072 & 0.2783 & 0.277 & 0.3471 \\
\hline Borehole C12 & 0.377 & 0.5925 & 0.6105 & 0.5202 \\
\hline Borehole C17 & 1.009 & 0.8555 & 0.905 & 1.0673 \\
\hline Borehole C37 & 0.320 & 0.4338 & 0.313 & 0.5411 \\
\hline Borehole C49 & 0.996 & 0.3945 & 0.58 & 0.4922 \\
\hline The influence distance (ft) & - & 250 & - & 281.85 \\
\hline Power & - & 2 & - & 131.05 \\
\hline RMSE & - & 0.31 & 0.25 & 0.26 \\
\hline$R$-squared coefficient (\%) & - & 22.83 & 48.02 & 44.43 \\
\hline MAPE (\%) & - & 85.35 & 69.51 & 78.11 \\
\hline
\end{tabular}

\section{Results and discussions}

\section{Case study}

Baba-Ali Iron Ore Mine (Hamedan Province, Iran) is located $35 \mathrm{~km}$ to the northwest of Hamedan. The mine includes two orebody parts, namely Baba-Ali 1 and Baba-Ali 2. Although the proven reserve of Baba-Ali 1 has been estimated to reach some 6 million tons of iron ore with an average grade of $59.14 \%$, the Baba-Ali 2 is being explored and evaluated deposit estimation. Figure 11 shows the geographical map of the Baba Ali iron mine in Iran. The deposit comprises iron ore with moderate to high breakage resistance, with the waste being mainly composed of diorite and calcsilicate with moderate to high breakage resistance. The deposit is part of the Sanandaj-Sirjan belt with a height of about $1950 \mathrm{~m}$ above sea level. The oldest rocks in the Baba-Ali deposit are limestone with the Cretaceous in age. The host rock of Baba-Ali iron mineralization is volcanic-sedimentary rocks of the Songhor series with Permotrriassic. The petrologic composition of these series includes felsic to intermediate volcanic rocks, often as lava and rhyolitic tuff, within interbedded carbonate layers and little tuffy sandstones. Emplacement and translocation of intrusions and subvolcanic rocks with the composition of gabbro-diorite, quartz-monzodiorite, granodiorite, syenite, syenogranite, and granite in this sequence during tectonic activities caused
Table 5 Cross-validation statistics for grade estimation

\begin{tabular}{ll}
\hline Cross-validation statistics for grade & \\
\hline Number of estimated samples & 32 \\
Number of not estimated samples & 0 \\
Mean of actual values & 38.0863636 \\
Mean of estimated values & 37.458668 \\
Mean difference (act - est) & 0.62769566 \\
Mean difference (as \% of actual) & 1.648 \\
Mean absolute difference & 10.2783342 \\
The variance of actual values & 359.090041 \\
The variance of estimated values & 184.889017 \\
Correlation coefficient & 0.65 \\
Kriging variance & \\
\hline Mean of estimated KV from the model & 319.076626 \\
Mean of squared differences & 209.03403 \\
Ratio & 1.526 \\
Regression equation & \\
Actual & $4.11638099+0.90686574 \times$ estimate \\
Standard error & 14.3887561 \\
\hline
\end{tabular}


Fig. 16 Result of Jack-knife kriging (actual data versus estimated data)

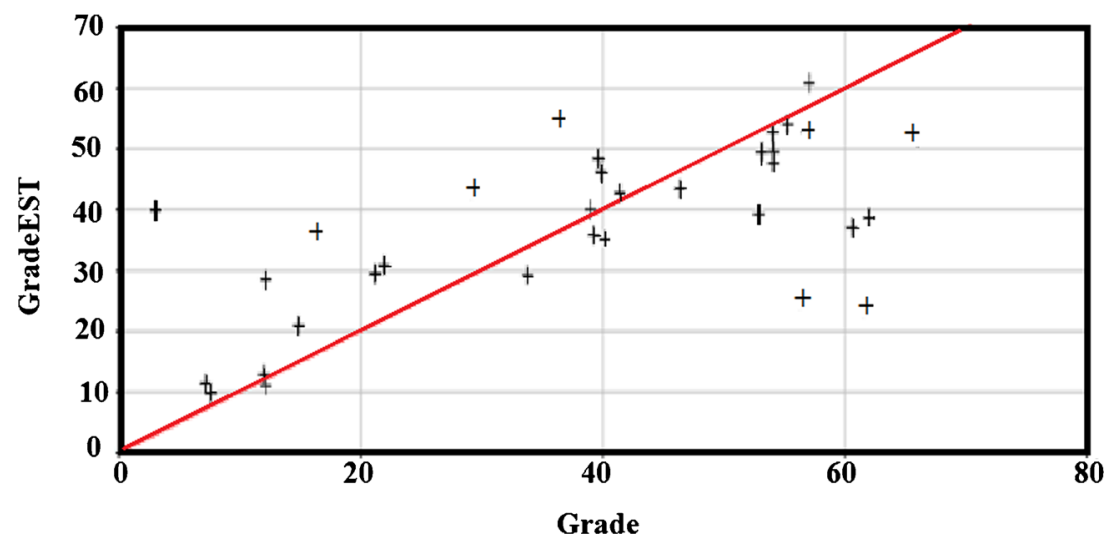

deformation and sometimes metamorphism of the Baba Ali region and iron ores (Rostami Paydar et al. 2010).

In the recent past, isolated exploration activities have been performed on this orebody. Among others, geological and geophysical maps of the mine have been prepared, a total of 21 magnetic sections have been surveyed, trenches have been excavated, surface and subsurface samples have been collected, and exploratory bores have been drilled. At the current time, a total of 120 bores were drilled in Baba-Ali Iron Mine. This study focused on section \#2390 because it hosted the most significant number of bores. Of the 32 bores drilled along this section, 27 bores were used for training the algorithm, and five bores were utilized for model validation. The estimation bores were selected in such a way to cover the model almost entirely. Figure 12 demonstrates the distribution of the bores along with section \#2390.

\section{Modeling results}

\section{Kriging}

Exploring the data gathered from the study area, three populations (with three different dimensions) were identified and used to scale the original data and estimation results (Fig. 13).

Once finished with the variography at different directions, two normal variograms along with two different azimuths 75 and $165^{\circ}$ were found and used to establish the searching ellipse (Fig. 14).

Once finished with variography, including the anisotropy angles, axis rotation direction, anisotropy radius (Fig. 15), and the nugget and ceiling effects, the searching ellipse was developed and used the basis for geostatistical estimations via kriging. Therefore, validation of these parameters was essential.

As is evident from the results, the validity of the variogram parameters for block grade evaluation was about $65 \%$, a desirable level of validity (Fig. 16 and Tables 4 and 5). This could be considered as a justification using the variogram parameters for the grade evaluation of exploratory blocks.

Residual analysis is used to investigate biases of the estimator in geostatistical modeling. Accordingly, an estimator can be recognized as unbiased if the histogram of the residuals (difference between actual data and estimated values) has a normal distribution around a mean value of zero with an adequately low standard deviation (Fig. 17).

\section{IDW}

For the considered reserve, the power and the radius of influence were set to 2 and $80 \mathrm{~m}$, respectively, and the grades were evaluated through Eq. (9).
Fig. 17 Histogram of residual distribution of the Jack-knife kriging algorithm (the results almost show the estimator is unbiased

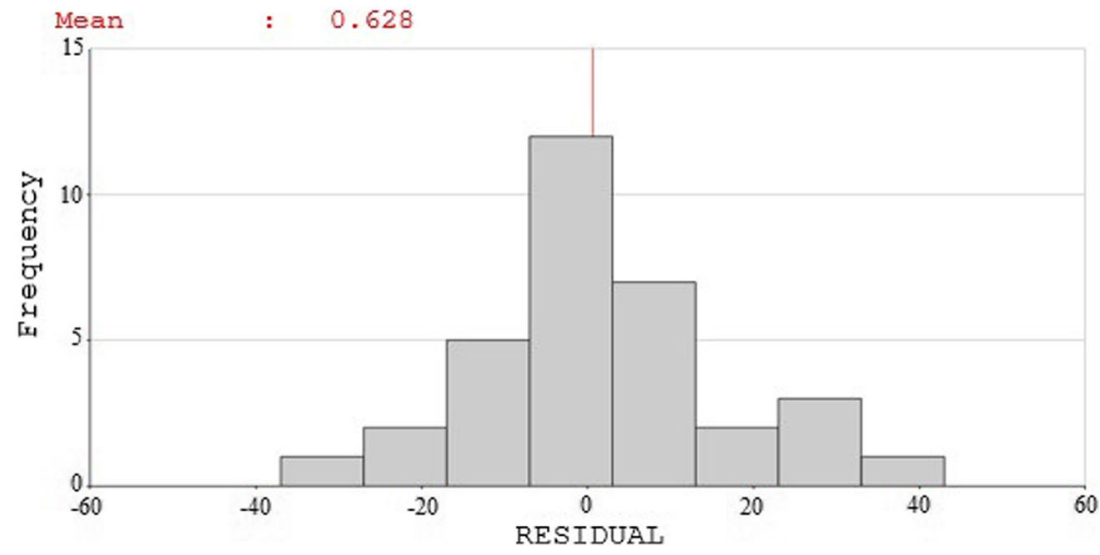


Table 6 Result of Jack-knife kriging (grade versus estimated grade)

\begin{tabular}{lll}
\hline NAME & Grade & GradeEST \\
\hline Minimum & 3.010 & 9.821 \\
Maximum & 66.000 & 60.848 \\
Mean & 38.086 & 37.459 \\
Correlation coefficient & 0.651 & \\
\hline
\end{tabular}

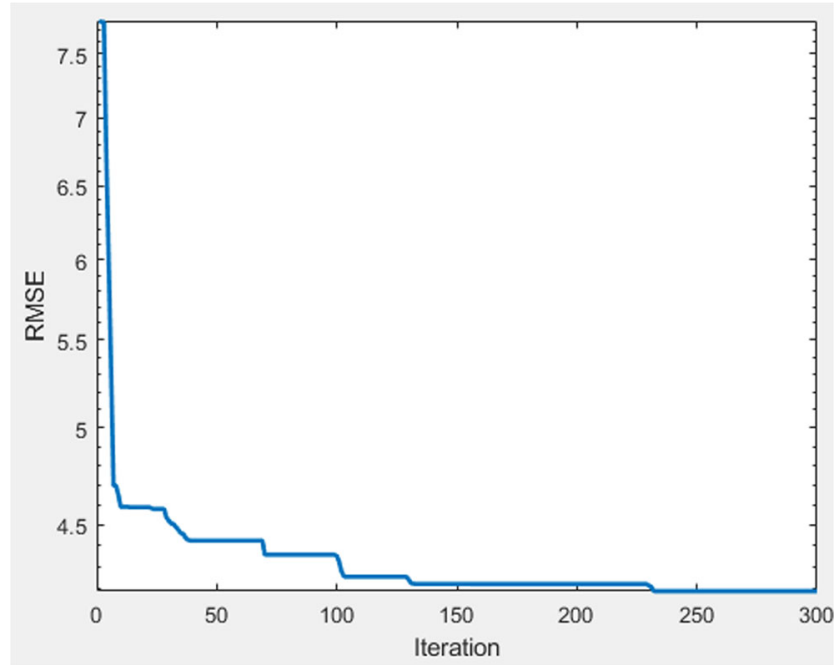

Fig. 18 A decreasing trend of RMSE while performing the ICA

\section{IDW-ICA results}

In the model, 50 countries, 9 imperialists, and 300 iterations were considered. The decreasing trend of RMSE during the
Table 7 The obtained results for Baba-Ali Iron Mine

\begin{tabular}{lllll}
\hline Parameter & Real data & IDW & Kriging & $\begin{array}{l}\text { IDW- } \\
\text { ICA }\end{array}$ \\
\hline Borehole BH1 & 38.96 & 43.13 & 43.25 & 36.23 \\
Borehole BH2 & 16.32 & 36.71 & 36.71 & 16.50 \\
Borehole BH3 & 21.90 & 39.23 & 28.54 & 29.89 \\
Borehole BH4 & 7.15 & 11.22 & 11.33 & 9.80 \\
Borehole BH5 & 57.04 & 61.46 & 60.85 & 53.97 \\
The influence distance (m) & - & 80 & - & 77.76 \\
Power & - & 2 & - & -181.34 \\
RMSE & - & 12.41 & 10.10 & 4.19 \\
$R$-squared coefficient (\%) & - & 51.02 & 67.53 & 94.41 \\
MAPE (\%) & - & 57 & 46.28 & 17.4 \\
\hline
\end{tabular}

performing the ICA is shown in Fig. 18. Figure 19 shows the distribution of the boreholes along with section \#2390 and the radius of influence of the estimated boreholes (Table 6).

The ICA results showed that the most suitable radius of influence was $77.76 \mathrm{~m}$ using this algorithm; Eq. (14) was developed for grade evaluation.

$$
g=\frac{\sum \frac{0.45828 \times g_{i}}{d_{i}^{-181.3350}}}{\sum \frac{0.52237}{d_{i}^{-181.3350}}}
$$

The boreholes, including $\mathrm{BH} 1, \mathrm{BH} 2, \mathrm{BH} 3, \mathrm{BH} 4$, and $\mathrm{BH} 5$ in the Baba Ali iron mine, were selected for the iron grade
Fig. 19 Distribution of the boreholes along with section \#2390 and the radius of influence of the validation boreholes

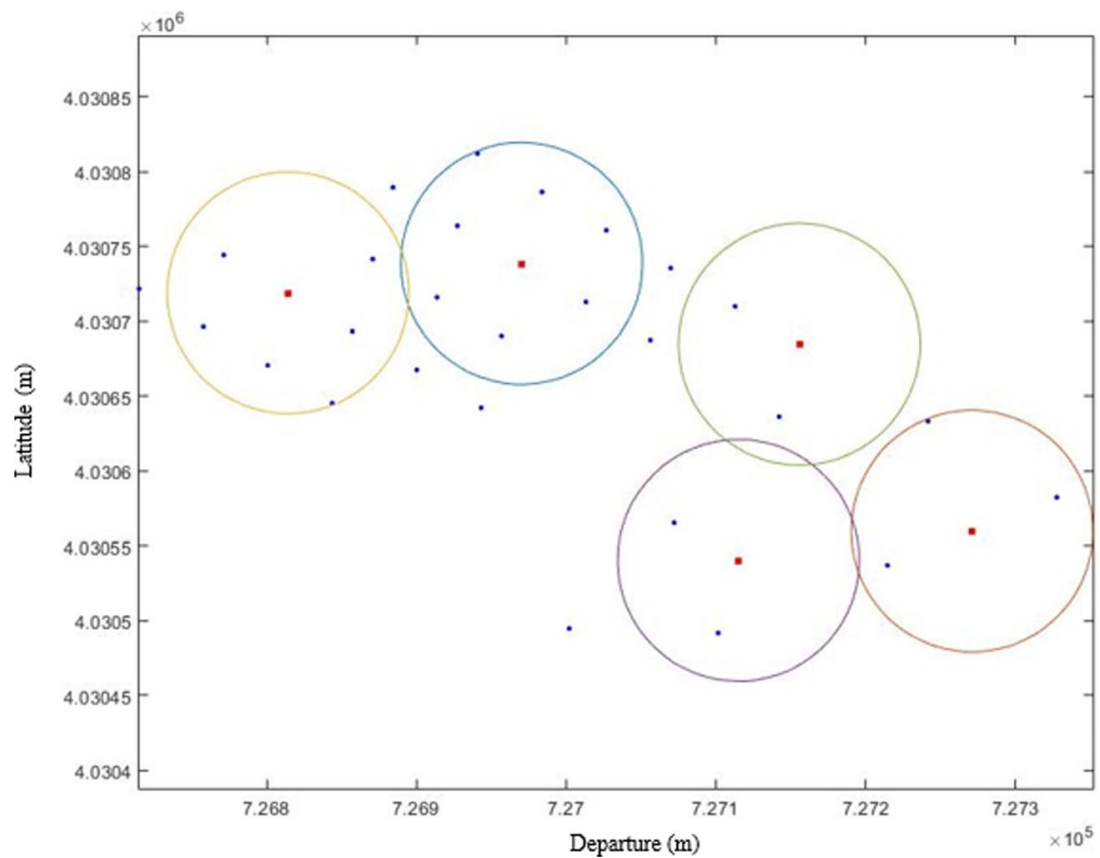


estimation by applying the IDW, the kriging, and the IDW-ICA methods. The power and the radius of influence values in the IDW were supposed to 2 and $80 \mathrm{~m}$, respectively (Hughes and Davey 1979). Also, the grade estimation by using the kriging technique was conducted by employing the Datamine studio software. Along with these two methods, the modifications of IDW's coefficients, power, and influence distance, $d_{i}$, were done by performing the ICA algorithm in the https://www.mathworks.com/products/matlab/student.html. As a result, the effective distance and power were calculated 77.6 $\mathrm{m}$ and -181.34 in the IDW equation, respectively. The estimated iron grades in the Baba Ali iron mine have been estimated by using the IDW, the kriging, and the IDW-ICA. The results have been presented in Table 7 . The real data referred to the actual iron grade in the boreholes. Some statistical parameters such as $R$-squared coefficients, RMSE, and MAPE were considered for evaluating the performance of the methods. As found from the table, the $R$-squared values in the IDW, the kriging, and the IDW-ICA were $51.02 \%, 67$. $53 \%$, and $94.41 \%$, respectively. Moreover, comparing the residual statistics, including RMSE and MAPE, revealed that the proposed technique, IDW-ICA, had the lowest values than the IDW and the kriging methods. By comparing the results, It is found that the IDW-ICA technique could estimate the grade values better than the IDW and the kriging.

\section{Conclusions}

In the present research, a new hybrid algorithm called IDW-ICA was proposed for grade estimation, and the following results were obtained:

- Considering the more accuracy, less time-consuming, and user-friendly use of the ICA algorithm, this technique was well capable of being used for grade estimation of the mineral orebodies.

- The classic IDW method with no accurate control on the evaluation parameters, including the influence distance and power, may lead to unrealistic results. Such unrealistic results may distract the designers and mining engineers in the design stage, leading to inappropriate mineral project assessment. For modifying the IDW, the coefficients were modified and found with the ICA algorithm. The higher values of $R$-squared coefficients and lower values of RMSE and MAPE revealed that the proposed method, IDW-ICA, had better estimations.

- For validating the proposed method, IDW-ICA, an example was solved by associating the IDW, the kriging, and IDW-ICA. The results showed that the IDW-ICA had better results than IDW, close to the kriging technique. Indeed, when the number of data points was low, it dropped drastically below the kriging as the number of data points increased.

- The obtained results of the grade estimations in the case study showed that the proposed hybrid algorithm, IDW-ICA, could be applied as a new-fangled method for grade estimation. It may lead to deciding with a high degree of confidence in mining projects.

Acknowledgements The authors would like to dedicate this manuscript to the third author, Dr. Mohammad Jalali, one of the youngest Iranian Geoscientists, who passed away at 36 in August 2020 due to the COVID19 pandemic. Moreover, the authors would like to express their appreciation to four anonymous reviewers for their constructive comments, which have improved the quality of the manuscript.

\section{Declarations}

Conflict of interest The author(s) declare that they have no competing interests..

\section{References}

Afeni TB, Akeju VO, Aladejare AE (2021) A comparative study of geometric and geostatistical methods for qualitative reserve estimation of limestone deposit. Geosci Front 12(1):243-253. https://doi. org/10.1016/j.gsf.2020.02.019

Ataei M, Osanloo M (2003) Determination of optimum cutoff grades of multiple metal deposits by using the Golden Section search method. J South Afr Inst Min Metall 103(8):493-499

Atashpaz-Gargari E, Lucas C (2007) Imperialist competitive algorithm: An algorithm for optimization inspired by imperialistic competition. IEEE Congress on Evolutionary Computation, pp 4661-4667. https://doi.org/10.1109/CEC.2007.4425083

Bartier PM, Keller CP (1996) Multivariate interpolation to incorporate thematic surface data using inverse distance weighting (IDW). Comput Geosci 22(7):795-799. https://doi.org/10.1016/0098-3004 (96)00021-0

Biabangard-Oskouyi A, Atashpaz-Gargari E, Soltani N, Lucas C (2009) Application of imperialist competitive algorithm for materials property characterization from sharp indentation test. Int J Eng Syst Simul 10(1):11-12

Chatterjee S, Bhattacherjee A, Samanta B, Pal SK (2006) Ore grade estimation of a limestone deposit in India using an artificial neural network. Appl GIS 2(1):2-1

Chatterjee S, Bandopadhyay S, Rai P (2008) Genetic algorithm-based neural network learning parameter selection for ore grade evaluation of limestone deposit. Min Technol 117(4):178-190. https://doi.org/ 10.1179/037178409X405732

Denby B, Schofield D (1995) Inclusion of risk assessment in open-pit design and scheduling. Int J Rock Mech Min Sci Geomech Abstr 5 (32): $230 \mathrm{~A}$

Gilani SO, Sattarvand J (2016) Integrating geological uncertainty in longterm open pit mine production planning by ant colony optimization. Comput Geosci 87:31-40

Hughes W, Davey R (1979) In: Crawford JT III, Hustrulid WA (eds) Drill hole interpolation: mineralized interpolation techniques, open pit mine planning and design. AIME, New York, pp 50-64

Jafrasteh B, Fathianpour N, Suárez A (2018) Comparison of machine learning methods for copper ore grade estimation. Comput Geosci 22(5):1371-1388. https://doi.org/10.1007/s10596-018-9758-0 
Jodeiri Shokri B, Dehghani H, Shamsi R (2020) Predicting silver price by applying a coupled multiple linear regression (MLR) and imperialist competitive algorithm (ICA). Metaheuristic Comput Appl 1(1): 101-114. https://doi.org/10.12989/mca.2020.1.1.101

Li XL, Li LH, Zhang BL, Guo QJ (2013) Hybrid self-adaptive learningbased particle swarm optimization and support vector regression model for grade estimation. Neurocomputing 118:179-190. https://doi.org/10.1016/j.neucom.2013.03.002

Mohammadi S, Kakaie R, Ataei M, Pourzamani E (2017) Determination of the optimum cut-off grades and production scheduling in multiproduct open pit mines using imperialist competitive algorithm (ICA). Res Policy 51:39-48. https://doi.org/10.1016/j.resourpol. 2016.11.005

Mohammadi NM, Hezarkhani A, Maghsoudi A (2018) Application of Kmeans and PCA approaches to estimation of gold grade in Khooni district (central Iran). Acta Geochim 37(1):102-112

Rostami Paydar G, Lotfi M, Ghaderi M, Amiri A, Vossoughi-Abedini M (2010) New results on mineralography and crystal chemistry of magnetite and pyrite at Baba-Ali \& Galali iron deposits, west of Hamedan, Iran. Sci Q J Geosci 20(77):121-130

Samanta B, Bandopadhyay S, Ganguli R, Dutta S (2004) Sparse data division using data segmentation and Kohonen network for neural network and geostatistical ore grade modeling in Nome offshore placer deposit. Nat Resour Res 13(3):189-200. https://doi.org/10. 1023/B:NARR.0000046920.95725.1b

Soleimani M, Jodeiri Shokri B (2015) 3D static reservoir modeling by geostatistical techniques used for reservoir characterization and data integration. Environ Earth Sci 74:1403-1414. https://doi.org/10. 1007/s12665-015-4130-3

Soleimani M, Jodeiri Shokri B (2016) Intrinsic geological model generation for chromite pods in the Sabzevar ophiolite complex, NE Iran. Ore Geol Rev 78:138-150. https://doi.org/10.1016/j.oregeorev. 2016.03.013

Tahmasebi P, Hezarkhani A (2010a) Application of adaptive neuro-fuzzy inference system for grade estimation; case study, Sarcheshmeh porphyry copper deposit, Kerman, Iran. Aust J Basic Appl Sci 4 (3):408-420

Tahmasebi P, Hezarkhani A (2010b) Comparison of optimized neural network with fuzzy logic for ore grade estimation. Aust J Basic Appl Sci 4(5):764-772

Zamanian H, Radmard K (2016) Geochemistry of rare earth elements in the Baba Ali magnetite skarn deposit, western Iran - a key to determine conditions of mineralisation. Geologos 22(1):33-47

Zerzour O, Gadri L, Hadji R, Mebrouk F, Hamed Y (2020) Semivariograms and kriging techniques in iron ore reserve categorization: application at Jebel Wenza deposit. Arab J Geosci 13(16):110. https://doi.org/10.1007/s12517-020-05858-x 